\title{
Development of a model for evaluating the effectiveness of innovative startups based on information cycles and using neural networks
}

\author{
Morozov Viktor, Kolomiiets Anna, Mezentseva Olga
}

Taras Shevchenko National University of Kyiv, Kyiv, Ukraine

\begin{tabular}{|c|c|}
\hline Article Info & ABSTRACT \\
\hline Article history: & An integrated approach to the creation and development of innovative startup \\
\hline Received Jan 19, 2021 & $\begin{array}{l}\text { projects in the field of information technology is considered. To conduct } \\
\text { research the authors proposed a model of information cycles of startup }\end{array}$ \\
\hline Revised Jun 7, 2021 & projects based on the creation of an information model of such projects. At \\
\hline Accepted Jun 14, 2021 & $\begin{array}{l}\text { the same time there are dynamic processes of changes in the parameters of } \\
\text { the model, which are turbulent in nature and require the use of tools and }\end{array}$ \\
\hline Keywords: & $\begin{array}{l}\text { methods of artificial intelligence for research. The key areas of knowledge of } \\
\text { such influence are defined. The mathematical model of processes of }\end{array}$ \\
\hline Efficiency & management of development of information technology (IT) startups on the \\
\hline Information cycles & basis of creation and development of a difficult IT product, taking into \\
\hline Information impacts & characteristics are allocated and parameters are defined. To do this, the \\
\hline Neural networks & construction of predictive models is proposed to be carried out by modified \\
\hline Project management & Demarc trends, the method of self-organization and the neural network. The \\
\hline Risks & modeling of the main objective functions of the mathematical model of these \\
\hline Startup projects & $\begin{array}{l}\text { processes is performed. The analysis of the received results is carried out and } \\
\text { the conclusions are made. }\end{array}$ \\
\hline
\end{tabular}

This is an open access article under the CC BY-SA license.

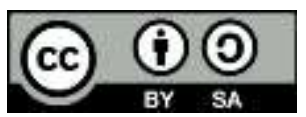

\section{Corresponding Author:}

Morozov Viktor

Department of Technology Management

Taras Shevchenko National University of Kyiv

24, Bohdan Gavrilishin str., Kyiv, 01601, Ukraine

Email:knumvv@gmail.com

\section{INTRODUCTION}

Analysis of the current experience of project management in Ukraine indicates the rapid development of project management methodologies, especially in the IT field [1]-[8]. A special place is occupied by methodologies for innovative startup projects (SUP) [2], which are associated with the analysis of numerous risk events [3] during the implementation of such projects. This is especially true in connection with the effect of quarantine measures in the context of the global COVID-19 pandemic [4], which significantly introduces unpredictability in the results of implementing already risky innovations [5]. But further development of humanity is not possible without innovation.

Today, the competitiveness of any company is somehow connected with an innovative approach [6] to solving business problems. A certain management methodology is necessary for startup performers to achieve the set results and implement the idea [7]. This is especially important for the high-tech industry, where startups are created in the form of ecosystems [8].

However, it should be noted that the creation of such ecosystems requires significant investment. The authors analyzed the statistics show that there are a number of risks that affect the results of the 
implementation of such projects, accordingly reduce the efficiency of investment in such projects and can reduce all efforts to create and develop IT products [9] of such projects to nothing.

A startup is a small company that tries to implement the founders business idea and is looking for a scalable business model [10]. The main feature of startups is innovation. Today, there is fierce competition in the market and most startups fail without reaching the product market fit (PMF) point (the state of the startup when it fully meets the needs of the market). In other words, the startup was unable to sell its product to potential customers and it turned out to be unnecessary for the market. The need for value for customers is one of the keys to promoting a startup in the market. According to research [11], 70\% of startups failed even before the start of the pandemic-related crisis, and the main reasons for their failure in the market are that the startup is not needed by the market (does not bring value to the user), lack of investment and a weak project team.

It should be noted that this article discusses a certain type of startups for companies with a business model of SaaS (software as a service) and B2B (business to business) [7]. Such companies have certain problems with long sales cycles of IT products, since the client's decision is collective and depends on many factors and conditions for using the startup's product for their own business. Therefore, the quality of customer service significantly affects the performance of such companies and is a complex indicator that depends on many factors. In addition, the B2B model in this case is characterized by customer experience, which is based on numerous interactions with the startup owner company.

So, to solve the problems of effectiveness of complex innovative startup projects in the field of high technologies, you should first outline the range of questions that need to be answered. Among others, such questions are related to attracting investment to startup projects [10], among which investment rounds are analyzed, and the difference in setting goals by startup management for selecting and attracting specific investors is explained. You should also pay attention to the expectations of investors, which are important for young companies to meet.

At the same time, the priority task for the development of startups in the development and implementation of modern integrated software applications is the availability of intelligent support that will allow optimizing costs [12] for such development and integration, as well as optimizing (reducing) the time for their development. This will dramatically affect the effectiveness of the development of an innovative IT product and becomes a top priority in modern market conditions.

The works of the following Ukrainian scientists were devoted to the development of modern project management methodologies [7], [13]-[17]. Considering the problems of managing startup projects in high-tech industries, we should focus on the works of such scientists as: [18]-[20]. The problems of improving the efficiency of project implementation using artificial intelligence methods to solve forecasting problems were devoted to the works of such scientists as [21]-[23].

Analysis of information sources [5]-[23] allows us to conclude that for effective management of complex innovative startups, there are really no integrated models and methods that allow us to respond to the turbulent impacts of the project environment at the lowest cost. This significantly reduces the opportunities for effective management of such projects. In turn, the possibilities of proactive management [24] in high-tech projects, which would allow taking into account complex dynamic impacts on the processes of product creation and project management, are insufficiently studied.

The purpose of the article is to substantiate and develop a conceptual model of information cycles for creating and developing innovative startup projects, to study the effectiveness functions of such projects using forecasting methods based on intellectual support tools. This approach will take into account the impact of numerical risks on the effectiveness of innovative projects, which in turn will take into account responses to dynamic changes and turbulence.

\section{RESEARCH METHOD}

As noted above, when making a decision on financing various types of startups, it is necessary to take into account not only the innovation of the created product or its versatility, but also to evaluate its effectiveness. However, in modern conditions of constant changes and various kinds of external influences, it is sometimes quite difficult to determine this clearly enough.

Under these conditions, the authors propose an information cycle model, iterative modeling of the stages of which will allow for a more accurate assessment of the state of startups with gradual forecasting of their parameters to assess performance. For this purpose, certain sets of data on the state of such projects at the stages of their creation and development will be recorded, with the ability to use such data sets for training intelligent tools. And with the help of these tools, it will be possible to predict the state of effectiveness of such projects and at the same time ensure a more accurate decision-making process regarding trench investment in such projects. An example of the proposed model can be shown in Figure 1. 
Considering the components of the proposed information cycle model, we can see that its first stage is to create a description of the elements of the information system. At the same time, the startup itself is considered as such a system. After creating such a description, you should define individual parameters that are affected by certain changes in the project environment. Such an environment changes all the time, these changes are poorly predicted and have a spontaneous and sometimes highly turbulent character.

Along with the fact that it is necessary to assess possible changes as a result of such impacts, it is necessary to simulate the state of the information system (Startup) and determine the predicted states of its parameters. This can be done thanks to a trained neural network [25], which is based on data from the initial stages of creating and developing a startup. In accordance with the assessment of the state of effectiveness of such a project, a decision is made whether to make such changes to the parameters of the Information System or not. Then this cycle can be repeated weekly.

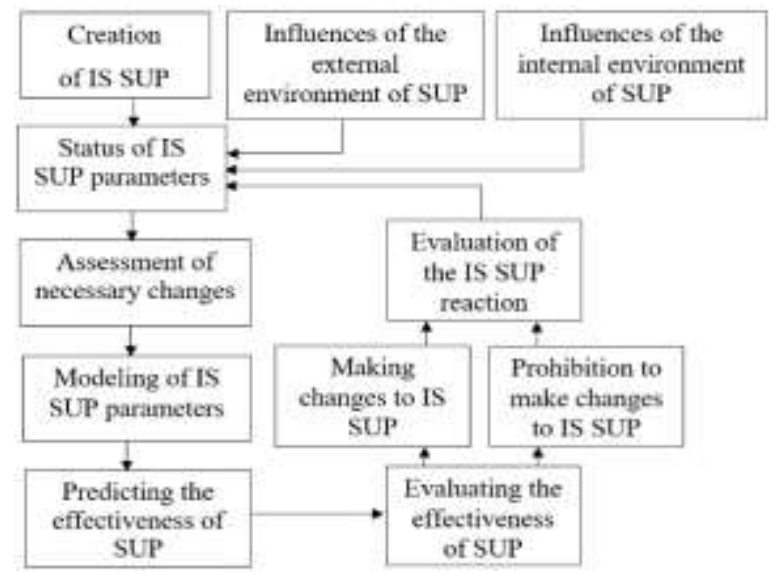

Figure 1. Model of the information cycle of ecosystem development SUP

Turning to the formal description of the proposed conceptual model, it should be noted that the vast majority of high-tech startups are associated with the creation of information systems (IS). Such systems, on the one hand, automate certain types of business activities, on the other hand, are the subject of certain research in order to model and improve the characteristics and parameters of the startup itself.

Let's assume that a certain type of such $I S$ can be represented as a given tuple,

$$
\mathrm{IS}=<\mathrm{P}^{\prime}, \mathrm{F}^{\prime}, \mathrm{IC}^{\prime}>
$$

where: $P^{\prime}$ - an information product that is the main value for the customer and forms the basis of $I S ; F^{\prime}$ information system functionality, which is represented by a set of business functions for processing incoming information until the desired commercial result is obtained; $I C^{\prime}-$ an information cycle that includes a list of processes for creating and developing a startup, as well as its product $P^{\prime}$.

Given the fact that each of these systems naturally develops over time, for effective management, it would be necessary to monitor the state of such a system during the processes of its creation and development until positive business results are obtained.With this in mind, you can use the following,

$$
\operatorname{IS}(\mathrm{t})=<\mathrm{P}(\mathrm{t}), \mathrm{F}(\mathrm{t}), \mathrm{IC}(\mathrm{t})\rangle
$$

where: $I S(t)$ - an $I S^{\prime}$ creation and development project that has clearly defined states at any given time $t$; $\mathrm{P}(\mathrm{t})$ - project product configuration [26], which consists of many elements with their own parameters and characteristics and which can change at any given time $t ; F(t)$ - information system functionality that provides users of the SaaS business model with a certain set of functions for developing their own business and such a set increases over time, that is $F(t)<F(t+1) ; I C(t)$ - state of the stages of the information cycle that determines the processes of managing the effectiveness of creation and development $I S^{\prime}$.

Despite the fact that $t \in T$, where $T$ - is the time horizon for managing the creation and development of a startup. The set $T$ itself can be represented,

$$
\mathrm{T}=\left\{\mathrm{t}_{0}, \mathrm{t}_{1}, \ldots, \mathrm{t}_{9}, \mathrm{t}_{10}, \ldots, \mathrm{t}_{\mathrm{i}}, \ldots, \mathrm{t}_{\mathrm{n}} ; \mathrm{i}=\overline{0, \mathrm{~N}} ; \mathrm{n} \in \mathrm{N}\right\},
$$


where: $t_{0}$ - period of formation and approval of the terms of reference for creating the system; $t_{1}-$ the period of creation of the project concept, goals, results and product of the system; the volume of investment, the rate of return and the viability of the project are determined; $t_{9}$ - stages of the eight phases of the standard IT project life cycle of a startup; $t_{10}$ - release period of the first system release; $t_{i}$ - startup product development periods; $t_{n}-$ final stage of Project Product Development; $N$ - the total number of stages of the management horizon for the creation and development of a startup. Based on the practice of developing such projects, the project management and support horizon is selected for three or four years. In our case, $\mathrm{N}=36$, that is, three years.

Thus, we can consider the monthly states of is $I S(t)$, during which the general system $I S^{\prime}$ prime has unchanged States from previous versions or its new releases (versions) are released. In this case, the information cycle at each stage can have the following form (in accordance with Figure 1),

$$
\operatorname{IC}\left(\mathrm{t}_{\mathrm{i}}\right)=\left\{\mp \Delta \mathrm{P}\left(\mathrm{t}_{\mathrm{i}}\right), \mp \Delta \mathrm{F}\left(\mathrm{t}_{\mathrm{i}}\right), \mathrm{C}\left(\mathrm{t}_{\mathrm{i}}\right), \mathrm{I}, \operatorname{Pr}\left(\mathrm{t}_{\mathrm{i}}\right), \mathrm{R}\left(\mathrm{t}_{\mathrm{i}}\right), \mathrm{Q}_{1}\left(\mathrm{t}_{\mathrm{i}}\right), \mathrm{Q}_{2}\left(\mathrm{t}_{\mathrm{i}}\right)\right\}
$$

where: $\mp \Delta \mathrm{P}\left(\mathrm{t}_{\mathrm{i}}\right)$ - removed or added components of a startup project product; $\mp \Delta \mathrm{F}\left(\mathrm{t}_{\mathrm{i}}\right)$ - removed or added business functions for system users; $C\left(t_{i}\right)$ - the cost of total costs for the development and maintenance of a startup, the development of new versions of the product, and so on; $I$ - total cost of initial investment in a startup, including refinancing; $R\left(t_{i}\right)$ - cumulative impact of risk events on the project at a given time $t_{i}$; $\operatorname{Pr}\left(t_{i}\right)$ - projected expected revenue from using a startup product; $Q_{1}\left(t_{i}\right)$ - total impact of the internal environment on project parameters and characteristics at a given time $t_{i} ; Q_{2}\left(\mathrm{t}_{\mathrm{i}}\right)$ - total impact of turbulent external environment on project parameters and characteristics at time $t_{i}$.

Among the main components of the information cycle considered, the most significant is the risk factor, which somehow accumulates the influence of the project environment, its reaction is an increase in the cost of the project and, of course, its assessment (action) affects the effectiveness of the project. Risk $R^{\prime}\left(t_{i}\right)$ project decisions on investing in a project at the stages of its creation and development in turbulence conditions are a set of descriptions of specific risks characterized by three main parameters [27],

$$
\mathrm{R}^{\prime}\left(\mathrm{t}_{\mathrm{i}}\right)=\left\{\left[\mathrm{s}_{\mathrm{i}} ; \mathrm{p}\left(\mathrm{s}_{\mathrm{i}}\right) ; \operatorname{Mr}\left(\mathrm{s}_{\mathrm{i}}\right)\right]\right\}
$$

where: $s_{i}$ - risk situation; $p\left(s_{i}\right)$ - degree of risk (assessment of the possibility of a risk situation); $\operatorname{Mr}\left(s_{i}\right)$ risk measure (assessment of the consequences of a risk situation). For projects with a higher level of risk, the company should use a higher discount rate $r_{i}$. At the same time, the discount rate used to account for risk depends on the type of project,

$$
r_{i}=r_{f}+R^{\prime}\left(t_{i}\right)
$$

where: $r_{f}$ - risk-free rate.

There is a need for structural multi-factor analysis of various risk factors and costs for anti-risk measures in order to make optimal management decisions in the course of investment and project activities. Let's present the profit $\mathrm{V}\left(t_{i}\right)$ project as income difference $\operatorname{Pr}\left(t_{i}\right)$ and the sum of three values: integral project costs excluding risk management costs $\mathrm{C}\left(t_{i}\right)$, integral project costs, taking into account the costs of risk prevention in stationary conditions $Q_{1}\left(t_{i}\right)$, integral costs of risk prevention in non-stationary conditions $Q_{2}\left(t_{i}\right)$ when $i=\overline{0, T}$ :

$$
\begin{aligned}
& \mathrm{R}\left(\mathrm{t}_{\mathrm{i}}\right)=\mathrm{R}^{\prime}\left(\mathrm{t}_{\mathrm{i}}\right)+\mathrm{C}\left(\mathrm{t}_{\mathrm{i}}\right)+\mathrm{Q}_{1}\left(\mathrm{t}_{\mathrm{i}}\right)+\mathrm{Q}_{2}\left(\mathrm{t}_{\mathrm{i}}\right) \\
& \mathrm{V}\left(\mathrm{t}_{\mathrm{i}}\right)=\operatorname{Pr}\left(\mathrm{t}_{\mathrm{i}}\right)-\left(\mathrm{R}\left(\mathrm{t}_{\mathrm{i}}\right)\right) \\
& \mathrm{V}\left(\mathrm{t}_{\mathrm{i}}\right)=\operatorname{Pr}\left(\mathrm{t}_{\mathrm{i}}\right)-\left(\mathrm{R}^{\prime}\left(\mathrm{t}_{\mathrm{i}}\right)+\mathrm{C}\left(\mathrm{t}_{\mathrm{i}}\right)+\mathrm{Q}_{1}\left(\mathrm{t}_{\mathrm{i}}\right)+\mathrm{Q}_{2}\left(\mathrm{t}_{\mathrm{i}}\right)\right)
\end{aligned}
$$

Evaluating the effectiveness of a project is based on plotting its cash flow in a time context, which determines the need for discounting. With this in mind, we will build a model for evaluating the effectiveness of an investment project, which makes it possible to take into account the structure of possible anti-risk measures. The mathematical expectation of a risk-adjusted discounted value can be written,

$$
\mathrm{M}\left\{\mathrm{V}\left(\mathrm{t}_{\mathrm{i}}\right)\right\}=-\mathrm{I}+\sum_{\mathrm{j}=0}^{3} \mathrm{p}_{\mathrm{j}} \sum_{\mathrm{t}=1}^{\mathrm{T}} \frac{1}{\left(1+\mathrm{r}_{\mathrm{i}}\right)^{\mathrm{t}}}\left\{\operatorname{Pr}(\mathrm{t})-\left[\mathrm{R}^{\prime}(\mathrm{t})+\mathrm{C}(\mathrm{t})+\mathrm{Q}_{1}(\mathrm{t})+\mathrm{Q}_{2}(\mathrm{t})\right]\right\}
$$

where: $r_{j}$ - discount rate (rate); $p_{j}$ - weighting factors that reflect the probability of each of the three scenario variants $(j=1,2,3)$ - optimistic, pessimistic, and most likely, respectively. To conduct a structural analysis of the costs of anti-risk measures, an integral risk cost optimization model can be used, which allows you to 
determine the expected value of the gross listed project costs for risk prevention $(P G C)$, on the basis of which the expected value of project costs for risk prevention will be,

$$
\mathrm{PGC}=\sum_{\mathrm{j}=0}^{3} \mathrm{p}_{\mathrm{j}} \sum_{\mathrm{t}=1}^{\mathrm{T}} \frac{1}{\left(1+\mathrm{r}_{\mathrm{i}}\right)^{\mathrm{t}}}\left\{\left[\mathrm{Q}_{1}(\mathrm{t})+\mathrm{Q}_{2}(\mathrm{t})\right]\right\}
$$

\section{SIMULATION RESULTS}

When making investment decisions, it is advisable to use not a priori information about the parameters that characterize the project under study, the enterprise and the economic environment as a whole, but their forecast. Usually, building a forecast of innovative startup projects involves a priori mathematical models. However, in the conditions of stochastic uncertainty of the turbulent environment of the project, it is necessary to use a different approach.

The most promising among mathematical methods, we considered the method of self-organization, neural networks and predictive trends of DeMarcus. The method of self-organizing models allows us to obtain a more accurate short-term forecast in comparison with DeMarcus trends [28]. The method is used in conditions of a narrowed volume of a priori information without taking into account significant factors. However, with sharp changes in the predicted process or an extremely small sample of data, DeMarcus trends show results of higher efficiency [29]. In both cases, a training and verification sample is used. The structure of modified DeMarcus trends looks like this:

$$
\mathrm{x}_{\mathrm{n}}=\mathrm{x}_{\mathrm{n}-1}+\mathrm{p}_{\mathrm{n}-1}
$$

where: $x_{n}$ - dynamic object state variable; $p_{n-1}-$ coefficient or function that characterizes the steepness of the trend. Using $p_{n-1}$ - the trend of changes in the state of a dynamic object, namely in our case $P G C$, is determined. Usually, DeMarcus forecasting trends are implemented on short measurement samples (2-10 measurements). Therefore, we used a modified demarcation trend used for a broader information Sample. it is advisable to use more complex methods for constructing models that allow you to get a more accurate predictive model. These methods include, in particular, the classical method of self-organization and neural networks.

When building and training a neural network, the main thing is to approximate the function [30]. Training takes place according to the following algorithm: i) the initial weights are randomly set; ii) the learning era is implemented; iii) the neural network shutdown condition is checked. For all input vectors (aggregates, neural network training epochs are performed in turn: i) the values of the input vector are passed through the network, we get the result of network operation; ii) there is a deviation of the network result from the original value; iii) the weights of connections of network elements change from the last layers to the first. The change occurs according to the gradient descent method. After completing the training era, the condition for the end of the algorithm's operation is checked. More precisely, how much the results of the neural network differ from the original values.

The first most important criteria are the criteria for evaluating the effectiveness of investment projects, which are unconditional requirements: the conditions of the investment situation, the volume of investments and the payback period. in one of the cases studied, for example, in conditions of stagflation, investment projects with short payback periods are mainly used. Therefore, for the Investor portfolio, projects are selected based on a discounted payback period (PP).

It was decided to use it for evaluating an investment project $I_{1}$ several criteria in the form of a total criterion at the same time. The significance of each specific criterion when evaluating an investment project is determined by its weight coefficient.

$$
I_{-} 1=a 1 R\left(t_{-} i\right)+a 2 V\left(t_{-} i\right)+a 3 P P+a 4 P G C+\cdots
$$

where: $I_{1}$ - total criteria for evaluating an investment startup project; $a_{1}, a_{2}, a_{3}, a_{4}$ - weighting factors.

Weighting factors have corresponding dimensions. Their values are determined from practical reports: the higher the coefficient, the more weight a particular criterion is included in the total criterion for evaluating an investment project. Such a balanced assessment of investment projects allows you to analyze all the proposed projects at once and get a numerical assessment of them.

It is proposed to first search for an approximate error minimum using the self-organization method, then initialize the weights of neural network connections obtained by values from the self-organization method, and find a more accurate approximation using neural network training. The self-organization method determines the bond weights using Gaussian normalization. For each combination of functions $F$, a model of the form is constructed, 


$$
\mathrm{F}_{\mathrm{m}}^{\mathrm{i}}=\mathrm{b}_{0}+\mathrm{b}_{1} \mathrm{~F}_{\mathrm{k}}^{\mathrm{i}-1}+\mathrm{b}_{2} \mathrm{~F}_{\mathrm{l}}^{\mathrm{i}-1}
$$

where: $b_{0}, b_{1}, b_{2}$ - weighting factors; $i$ - algorithm step number; $k, l, m$ - function indexes within Sets; $i$-th and $i$ - 1 -st steps of the algorithm, and the index $k$ should not coincide with $l$. Combining the results of the transition from one step to another continues as long as the error obtained using the test sample decreases. After the algorithm is completed, you need to go through all the steps of the algorithm in reverse order and determine the weights for the basic functions.

It should be noted that the self-organization method learns differently from a neural network. The method is based on Gaussian normalization and selection of the best results, while the neural network is based on the reverse propagation method and the gradient descent method. The type of neural network that has the appropriate structure for combination with the self-organization method is the Volterra network. It allows you to use the result of the self-organization method as a starting point for training a neural network as shown in Figure 2. The process of dynamic construction and training of the Volterra network can be represented as a flowchart.

One of the problems that is solved using the Volterra network is the problem of predicting variables over time. The task is to process retrospective information about an object, establish a relationship between the state of this object in the future and states in previous periods. Dynamic processes occurring in startup projects, in particular in their external environment, create the effect of increasing requirements for the maneuverability of their modeling. For programming such conditions for training a neural network of this kind, the most convenient and functional Python library is NumPy as shown in Figure 3. The undoubted advantages are: support for multidimensional arrays (including matrices), support for high-level mathematical functions designed to work with multidimensional arrays.

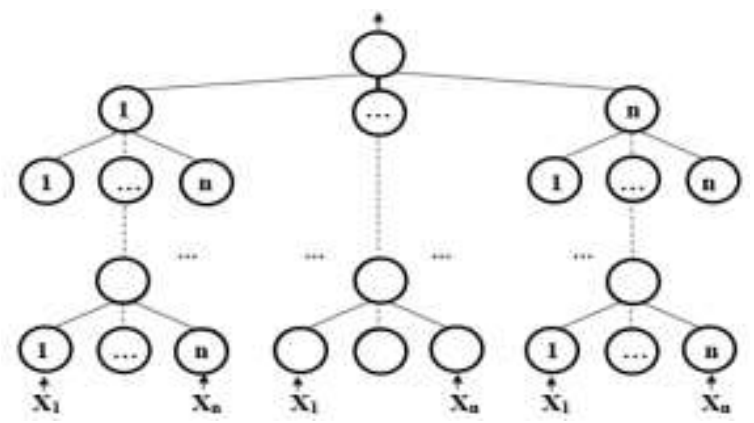

Figure 2. Structure of the volterra network

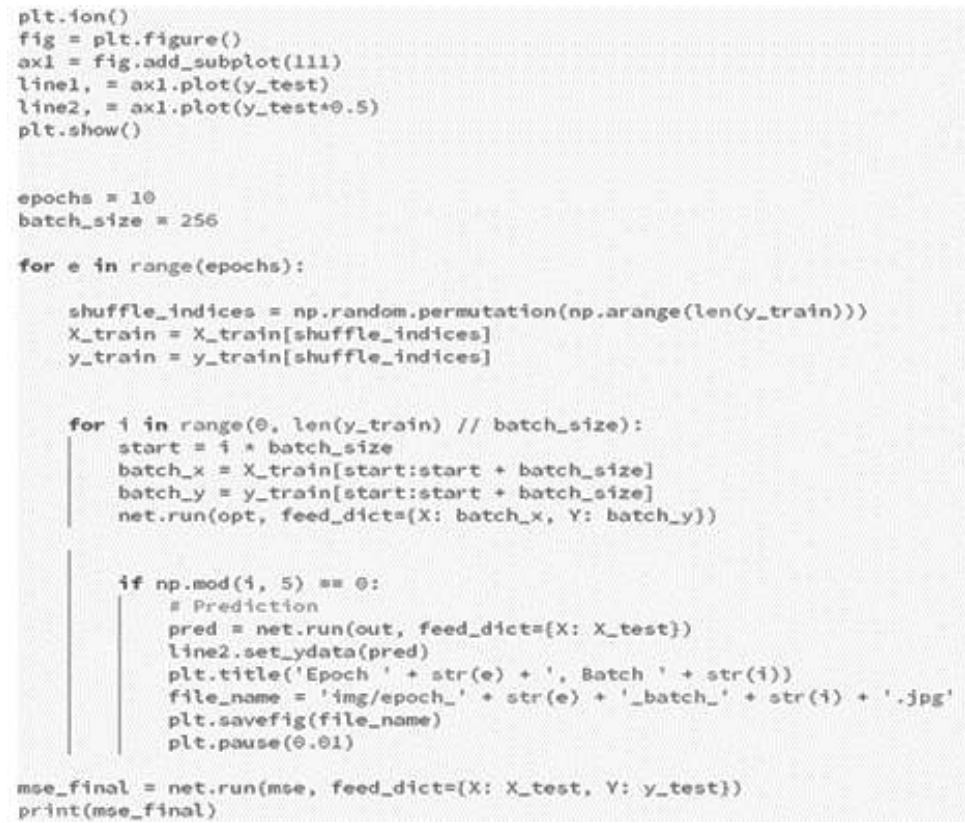

Figure 3. Listing the program code of the part of network training that should stop when the maximum number of epochs is reached or when another pre-defined stop criterion is triggered

Development of a model for evaluating the effectiveness of innovative startups based on ...(Morozov Viktor) 
The results of the study showed that the quality of forecasting depends as shown in Figure 4 on the $\Omega$-rate of error change, since its value is involved in making the decision to add a layer. The best forecast quality is achieved at $\Omega=0.004$. it is also obvious that the accuracy of the forecast will increase with increasing training epochs. Calculations have shown that in the short term (from the startup implementation stage), graphs 1,2 , and 3 coincide with an accuracy of $\delta=10^{-3}$. Thus, the practical recommendations for using Volterra network modeling obtained in relation to the model (16-19) can be applied in studying the effectiveness of innovative startup projects (sups) with a turbulent environment.

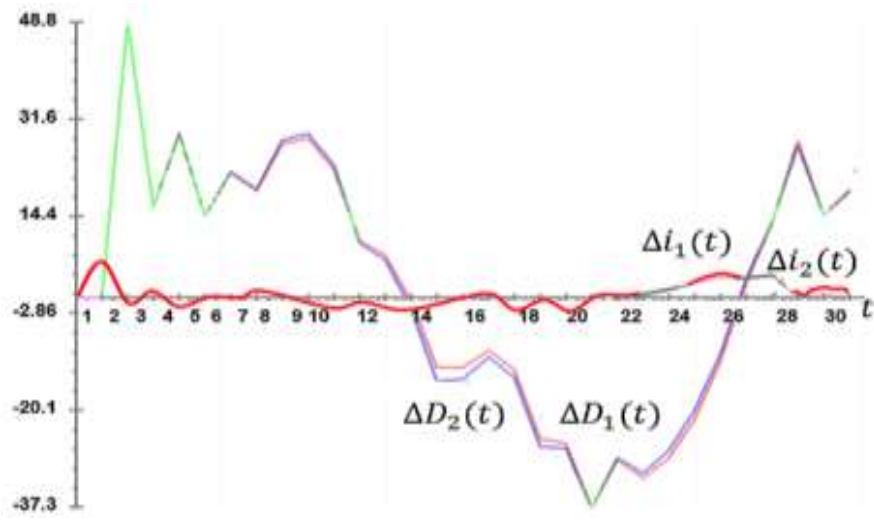

Figure 4. Graphs of network predictions based on training and test samples. Training sample: blue-real values, pink-predicted values. Test sample: green-real values, pink- provided

\section{RESULT AND DISCUSSION}

The research conducted by the authors shows that models based on information cycles should be used to build models of active impact on the effectiveness of high-tech projects in the form of startups for business models based on SaaS and B2B. When applying the developed mathematical models in practice, it was possible to significantly influence the effectiveness of high-tech startups with a significant reduction in investment risk. identified:

As a result of modeling, the following results are obtained and the following relationships are

- The total cost of initial investment in a startup, including refinancing, has almost no impact on the total riskiness of the project;

- The cumulative impact on the project of risk events at a time directly flagged or with an increasing coefficient (1.3-1.5) is related to the projected expected income from using the startup product, especially at the stage of launching the product to the market;

- The total impact of the turbulent external environment on the parameters and characteristics of the project reduces the term of possible profitability by up to $64 \%$, provided that the cumulative impact of risky events on the project increases;

- Break-even of a startup project becomes more affordable if the project's working capital increases.

\section{CONCLUSION}

To successfully make a decision on the implementation of the investment process, it is necessary to have a reasonable forecast of the development of the situation in the future. For this purpose, it is proposed to build predictive models using DeMarcus trends, modified DeMarcus trends, the self-organization method, and the Volterra neural network. A general criterion for evaluating investment projects is proposed, which includes defining criteria that characterize the investment project itself and determine the investment attractiveness of the organization. The authors of the study of the proposed models and forecasting methods have shown their effectiveness and can be used in practice when considering other startup projects in various fields of technical activity.

As further research, it should be noted that there is a need to identify the processes involved in creating complex IT Products, project management processes involving constant dynamics of changes in interaction with turbulent environments and their mutual influence. 


\section{REFERENCES}

[1] Project Management Institute, A Guide to the Project Management Body of Knowledge, 6th ed. Pennsylvania, USA: Project Management Institute, 2017, pp. 586.

[2] M. Lukes, M. C. Longo, and J.Zouhar, "Do business incubators really enhance entrepreneurial growth? Evidence from a large sample of innovative Italian start-ups," Technovation, vol. 82, pp. 25-3, 2019, doi: 10.1016/j.technovation.2018.07.008.

[3] A. Kolomiiets and V. Morozov, "Investigation of optimization models in decisions making on integration of innovative projects," Advances in Intelligent Systems and Computing, AISC, vol. 1246, pp. 51-64, 2020, doi: 10.1007/978-3-030-54215-3.

[4] R. G. Cooper, Winning at new products: Creating value through innovation, New York, USA: Basic Books, 2017.

[5] M. Antikainen and K. Valkokari, "A Framework for Sustainable Circular Business Model Innovation," Technology Innovation Management Review, vol. 6, pp. 5-12, 2016, doi:10.22215/timreview/1000.

[6] J. Spender, V. Corvello, M. Grimaldi, and P. Rippa, "Startups and open innovation: a review of the literature," European Journal of Innovation Management, vol. 20, no. 1, pp. 4-30, 2017, doi: 10.1108/EJIM-12-2015-0131.

[7] V. Morozov, O. Mezentseva, and M. Proskurin, "Trainable Neural Networks Modelling for a Forecasting of StartUp Product Development," 2020 IEEE Third International Conference on Data Stream Mining \& Processing (DSMP), 2020, pp. 55-60, doi: 10.1109/DSMP47368.2020.9204264.

[8] S. Nambisan, K. Lyytinen, A. Majchrzak, and M. Song, "Digital Innovation Management: Reinventing Innovation Management Research in a Digital World," MIS Quarterly, vol. 41, no. 1, pp. 223-238, 2016.

[9] N. Paternoster, C. Giardino, M. Unterkalmsteiner, T. Gorschek, and P. Abrahamsson, "Software Development in Startup Companies: A Systematic Mapping Study," Information and Software Technology, vol. 56, no. 10, pp. 1200-1218, 2014, doi: 10.1016/j.infsof.2014.04.014.

[10] S. Blank and B. Dorf, The Startup Owner's Manual: The Step-By-Step Guide for Building a Great Company (DIATEINO), Pescadero, California: K \& S Ranch, 2012, pp. 608.

[11] K. Swani, B. P. Brown, and S. M. Mudambi, "The untapped potential of B2B advertising: A literature review and future agenda,” Industrial Marketing Management, vol. 89, pp. 581-593, 2019, doi: 10.1016/j.indmarman.2019.05.010.

[12] V. V. Morozov, O. V. Kalnichenko, and O. O. Mezentseva, "The method of interaction modeling on basis of deep learning the neural networks in complex IT-projects," International Journal of Computing, vol. 19, no. 1, pp. 88-96, 2020, doi: 10.47839/ijc.19.1.1697.

[13] V. Burkov, et al., Resource management of distributed projects and programs in Russian Управление ресурсами распределенных проектов и программ, Ukraine: Nikolaev, Publisher Vasiliy Torubara, 2015, pp. 338.

[14] N. Yehorchenkova, I. Teslia, and O. Yehorchenkov, "Method of project and operational processes integration in the activities of project-oriented enterprises based on functional 4P-environment," ITPM, pp. 142-151, 2020.

[15] A. S. Hilaiwah, H. A. Alwally Abed Allah, B. A. Abbas, and T. Sutikno, "Live to learn: learning rules-based artificial neural network," Indonesian Journal of Electrical Engineering and Computer Science, vol. 21, no. 1, pp. 558-565, 2021, doi: 10.11591/ijeecs.v21.i1.pp558-565.

[16] H. A. Almurieb and E. S. Bhaya, "Best neural simultaneous approximation," Indonesian Journal of Electrical Engineering and Computer Science (IJEECS), vol. 20 no. 3, pp. 1584-1590, 2020, doi: 10.11591/ijeecs.v20.i3.pp1584-1590.

[17] O. Sherstyuk, T. Olekh, and K. Kolesnikova, "The research on role differentiation as a method of forming the project team," Eastern-European Journal of Enterprise Technologies, vol. 2, no. 80, pp. 63-68, 2016, doi: 10.15587/1729-4061.2016.65681.

[18] E. Ries, The Lean Startup: How Today's Entrepreneurs Use Continuous Innovation to Create Radically Successful Businesses, Redfern, New South Wales, Australia: Currency, 2011, pp. 336.

[19] M. Unterkalmsteinera, P. Abrahamssonb, and X. Wangc, "Software Startups-A Research Agenda," E-Informatica Software Engineering Journal, vol. 10, no. 1, pp. 89-123, 2016, doi: 10.5277/e-Inf160105.

[20] S. Neslin, "Defection Detection: Measuring and Understanding the Predictive Accuracy of Customer Churn Models," Journal of Marketing Research American Marketing Association, vol. 43, pp. 204-211, 2006, doi: $10.1509 / j m k r .43 .2 .204$.

[21] C. Wei and T. Chiu, "Turning telecommunications call details to churn prediction: A data mining approach," Expert Systems with Applications, vol. 23, no. 2, pp. 103-112, 2002. doi: 10.1016/S0957-4174(02)00030-1.

[22] G. Greco, A. Guzzo, L. Pontieri, and D. Sacca, "Mining Expressive Process Models by Clustering Workow Traces," Lecture Notes in Computer Science, vol. 3056, pp. 52-62, 2004, doi: 10.1007/978-3-540-24775-3_8.

[23] J. Brownlee, Why One-Hot Encode Data in Machine Learning?, Machine Learning Mastery, 2017. [Online]. Available at: https://machinelearningmastery.com/why-one-hot-encode-data-in-machine-learning/

[24] IT Expert Training and examination center, Proactive Project Management. [Online]. Available: https://www.itexpert.ru/rus/ITEMS/200810062247/

[25] A. H. Alsaeedi, A. H. Aljanabi, M. E. Manna, and A. L. Albukhnefi, "A proactive metaheuristic model for optimizing weights of artificial neural network," Indonesian Journal of Electrical Engineering and Computer Science (IJEECS), vol. 20, no. 2, pp. 976-984, 2020, doi: 10.11591/ijeecs.v20.i2.pp976-984.

[26] Project Management Institute, Practice Standard for Project Configuration Management, Newtown Square, USA: Project Management Institute, 2007, pp. 61.

[27] S. Manikam, S. Sahibudin and V. Kasinathan, "Business intelligence addressing service quality for big data analytics in public sector," Indonesian Journal of Electrical Engineering and Computer Science (IJEECS), vol. 16, no. 1, pp. 491-499, 2019, doi: 10.11591/ijeecs.v16.i1.pp491-499.

[28] T. R. DeMark, Technical analysis-new science, New Jersey, USA: John Wiley, 1994. 
[29] A. G. Ivakhnenko and Y. A. Muller, Self-organization of predictive models in Russian Самоорганизация прогнозных моделей, Kiev: Technika, 1985.

[30] K. A. Newspin and J. L. Weiss, "Modification of the neural network technique of self-organization," in Automation and Modern Technologies in Russia Автоматизачия и современные технологии, Moscow: Mashinostroenie, 2007, pp. 8.

\section{BIOGRAPHIES OF AUTHORS}

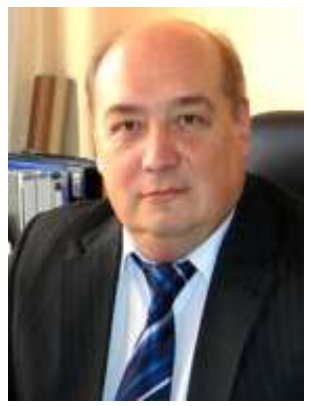

Viktor Morozov, Ph.D., professor, Head of Dept. of Technology Management of Faculty of Informational Technology of Taras Shevchenko National University of Kyiv, Ukraine. He has a teaching and research experience managing complex projects for more than 30 years. He is the author of over 240 articles in various international journals and editions of well-known national and international conferences. Author of seven monographs and six textbooks in the field of information technology and IT project management. Current research interests include problems of complex distributional IT projects with using cloud technology and methods of artificial intelligence. Co-organizer of five international conferences on information technology and interaction. Member of IEEE.

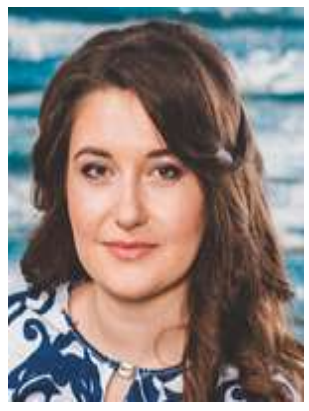

Anna Kolomiiets, Ph.D., Associate professor of Dept. of Technology Management of Faculty of Informational Technology of Taras Shevchenko National University of Kyiv, Ukraine.

Received an MSc degree in Cybernetics from the National Technical University of Ukraine "Igor Sikorsky Kyiv Polytechnic Institute", Ukraine in 2011. Received PhD degree in 2015 and since 2015, she is a lecturer of the Faculty of Information Technology, Taras Shevchenko National University of Kyiv, Ukraine. Author of more than 60 scientific and methodological works, including 2 monographs, 2 textbooks, a number of publications in domestic and foreign scientific collections. Her research interests include project management, information technologies, business analytic.

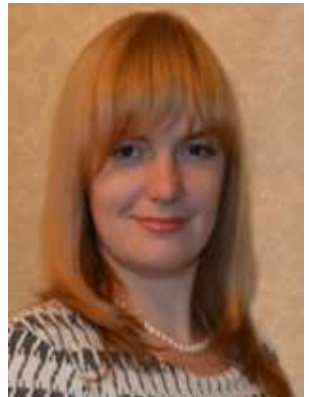

Olga Mezentseva, Ph.D., Associate professor of Dept. of Technology Management of Faculty of Informational Technology of Taras Shevchenko National University of Kyiv, Ukraine. For successes in teaching and research activity, the author was awarded a scholarship of the Verkhovna Rada of Ukraine and a scholarship of the President of Ukraine. Author of more than 50 scientific and methodological works, including 3 monographs, a number of publications in domestic and foreign scientific collections, including 7 in the scientometric database Scopus. Olga actively participates in international conferences, the achievements of which are indexed in the Scopus and WoS reference databases and plans to continue this work fruitfully. In terms of publication activity. The priority area of scientific research on priority areas of science and technology development is the direction: information and communication technologies. 